This is an electronic reprint of the original article. This reprint may differ from the original in pagination and typographic detail.

Author(s): Maunula, Minna

Title: $\quad$ Everyday Family Life and Multiple Roles of the Female Doctoral Students

Year: $\quad 2017$

Version:

Please cite the original version:

Maunula, M. (2017). Everyday Family Life and Multiple Roles of the Female Doctoral Students. In L. G. Chova, A. L. Martínez, \& I. C. Torres (Eds.), EDULEARN17 Proceedings. 9th International Conference on Education and New Learning Technologies (pp. 694-701). IATED Academy. EDULEARN proceedings. https://doi.org/10.21125/edulearn.2017.0115

All material supplied via JYX is protected by copyright and other intellectual property rights, and duplication or sale of all or part of any of the repository collections is not permitted, except that material may be duplicated by you for your research use or educational purposes in electronic or print form. You must obtain permission for any other use. Electronic or print copies may not be offered, whether for sale or otherwise to anyone who is not an authorised user. 


\title{
EVERYDAY FAMILY LIFE AND MULTIPLE ROLES OF THE FEMALE DOCTORAL STUDENTS
}

\author{
Maunula Minna \\ University of Jyvaskyla, Kokkola university consortium Chydenius (FINLAND)
}

\begin{abstract}
Combining work and family life, and the challenges and solutions connected to it is a topical and globally significant subject. In the article I examine how the under 40 -year-old female doctoral students with a family succeed in combining their roles as a mother and a doctoral student in their own everyday lives. A number of large and simultaneous challenges condense in the everyday life of an under 40-year-old female doctoral student with a family. In the examination I concentrate on the everyday challenges of the female doctoral student, on the interface of the family and the doctoral studies and on the choices made in everyday life. The qualitative research material consisted of the theme interviews of 12 female doctoral students with a family. The theme interview is suitable for examining a wide and multi-dimensional subject matter. The study is phenomenological with loose hermeneutic and narrative connections. Nowadays the atmosphere of planning is pervasive and an individual is expected to plan their life course precisely. The work career should be carefully planned out, the family established with consideration and the different sectors of the life course combined into a meaningful and active whole. The choices that are made in everyday life spring partly from the evaluations of past events and from the anticipations of the future. On the basis of the study it would seem that the female doctoral student succeeds most in accommodating the family and private life, if she is working as a full time researcher and conducts the doctoral thesis research as her main employment through the regular working hours. Research in addition to work congests other aspects of life and often overshadows it.
\end{abstract}

Keywords: doctoral student, individual, everyday, family life.

\section{INTRODUCTION}

What is the life of an under 40-year-old woman with a family studying for a doctoral degree like? Establishing a family changes at least the women's life course. Simultaneously, there are several demanding yet meaningfully challenging factors, which must be organized to overlap in the everyday life of a female doctoral student with a family. Nowadays the life should be controlled and effectively planned: the work career should be built deliberately and the family started at the right time. Nowadays the atmosphere of planning is pervasive and an individual is expected to plan their life course precisely. The work career should be carefully planned out, the family established with consideration and the different sectors of the life course combined into a meaningful and active whole. The choices that are made in everyday life spring partly from the evaluations of past events and from the anticipations of the future.

\section{INDIVIDUAL CONSTRUCTION OF EVERYDAY LIFE}

\subsection{Women in the Changing Doctoral Studies}

In the 2000s the universities have been strongly effeminized and about half of the doctoral students are women, although the disciplines have become differentiated by gender and the professoriate is still dominantly male [1]. The global objective is the efficient graduation of multi-skilled and expert doctors within the set target time and the better relevance of doctoral degrees to working life [2]. Doctoral education is developed by comparing the best qualities of the systems in different countries and by combining functional entities from them. In spite of the aspirations for unifying the doctoral studies, the doctoral processes are multiform in practice in different countries. Otherwise, there is also a change in progress in the production of doctoral degrees which leads to the non-academic career of more and more doctors [3; 4].

Alongside the general education policy and the economic research objectives, attention should be paid to the doctoral student's individual and life course perspectives. For example, women no longer 
need to make a choice between a career and a family. Nowadays there are better opportunities than before to choose both and to build individually functioning everyday life, which is, however, marked off by certain realities. The problems associated with combining the family and the demanding scientific work have been thought about for a long time but the subject is still topical, for example, for the sake of global competition development and increasing individuality.

\subsection{The Individual Family and Family Life}

The time of starting a family has become later and the equality inside the families has developed. In the two career families the lack of time and the negotiations about its use are a part of everyday life. [5.] The family and the children do not automatically weaken the woman's status because individual and internal choices in the families are possible. Fathers are also willing to postpone their career development and to concentrate on the family. [6.] The interaction of work and family can be examined through the work and family roles [7] as well as through the multiple roles, and an understanding that is more dynamic than before can be arrived at. Work and family roles can complement each other and provide opportunities for growth for both the parents. Multiple roles reward and protect in the changing situations in life. A balanced family life also helps in managing in the working life. In managing the interface of work and family, the active role of an individual who is able to adapt to different environments and to shape the operational environments is emphasized. [8; 5.]

\subsection{Individual Everyday Life}

The individual and diversified life course does not offer traditional, ready models for everyday life. Indeed the individual objectives strongly direct the everyday operation, where the compulsiveness and methodicalness of choice are emphasized. [9.] Simultaneously, the challenges of everyday life are increased by the constantly changing conditions, the life's changing pillars of foundation and the updating of individual priorities. The uncertainty and difficulty in anticipation requires the adoption of a fresh attitude. [8.]

The understanding of the past, the idea of the future or the possible futures and their connection with the present help in different situations of choice [10]. Still, the stability that has been associated with adulthood and the clarity of the future hopes waver. Even the most carefully drawn up plans can prove to be useless [11], though, on the other hand, the success at the earlier stages of the life course strengthens the confidence in one's own abilities and capacity to manage. The compulsion of choice becomes concrete when the wholeness of everyday life is examined. The everyday challenges of a female doctoral student are connected to combining the separate roles: the family, studies, work and spouse demand the investment. The constant balancing in everyday life is closely present, the individual everyday life consists of individual choices. The everyday life is ordinary, habits and practices as well as gendered operation [12].

\section{METHODOLOGY}

The qualitative research material consisted of the theme interviews of 12 female doctoral students with a family. The theme interview is suitable for examining a wide and multi-dimensional subject matter. The advantage of the theme interview is the personal interaction between the researcher and the ones to be examined, as well as its flexibility. It is possible to acquire nuanced information about the life of the ones to be examined through their own expressions on the theme interview [13]. All the interviews began similarly but proceeded flexibly through the individual themes and emphases in the different sectors and time dimensions of the life course.

The research material includes doctoral students from three Finnish universities, both from the hard, explanatory natural science faculties as well as from the soft disciplines which increase understanding. The doctoral students were at different stages in their studies. Some had just begun their study, some had agreed the date for the argumentation. The majority of the interviewees were married. The number of children varied from one to three. The interviewees' average age was 32 years. They had begun their postgraduate studies immediately after having qualified with a Master of Arts or at the latest after a year. The multiple levels of many roles were current in the lives of all who were examined and several roles were seen to have continuity also in the future. Seven out of the twelve students conducted their research as paid work in the university, two with a scholarship, one student whilst being unemployed, one was on a family leave and one in addition to other work. The situations can 
change rapidly, among others, because of short, fixed term employment, scholarship periods and family leaves.

The study is phenomenological with loose hermeneutic and narrative connections. Phenomenological study concentrates on the views of the individual and on the experiences from their own point of view [14]. In a phenomenological examination the perception of more general and deeper significances is attempted through an individual phenomenon. The individual case is an example of the general one. [15]. Hermeneutics is connected to the interpretation of the study and to the objective to understand. Narrative features, however, are seen in how the interviewees told "their own story" through the different themes and partly through the wholeness of their life course [16]. There are narrative features also in the future thinking: the interviewees perceive the matters temporally as continuum and as narratively intelligible wholeness.

\section{RESULTS}

The text included in the sections or subsections must begin one line after the section or subsection title. Do not use hard tabs and limit the use of hard returns to one return at the end of a paragraph.

\subsection{Everyday Family and Doctoral Studies Combinations}

The experience of doctoral study experience is an individual one. It is affected by the earlier experiences of studying and research, expectations, visions, the field and situation in life. Numerous factors are reflected in the experience and it is not possible to individually identify all of them. [17.]

The women in my study disliked the concept of "a doctoral student". They defined themselves as researchers. In addition to it, they perceived themselves as mothers. The experience of the doctoral studies was connected to the stage of studies. The research work proceeds in cycles and sometimes one's own knowledge and skills are put to the test. The ones in the beginning and in the middle of the process told that they were carrying out their doctoral studies at a strict pace and they did not experience any particular problems in everyday life. Instead, the ones at the final stage of the process experienced considerable hurry and stress. In particular, finding employment after graduating and the situation in life taking a new shape were causes of worry.

\subsection{Children as Part of the Everyday Life}

Seven of the women had children already before becoming doctoral students and another seven had a child or children during their doctoral studies. They recounted that at the university they had received astonished reactions about their timing of having children. The majority of the students participating in the study told that the first child in the family was born without planned schedules. However, since the family life has also become a project, having children should also be planned and be prepared for [18]. The longing for motherhood combines conflicting hopes: through motherhood the significance and warmth of life are aimed for and, on the other hand, individuality is realized [8]. In any case, motherhood changes the woman's everyday life, identity, human relations and creates conflicts in the woman's life [19]. For the women interviewed by me, having a child and being on family leave gave them time to think about life and about their own career aspirations. However, the doctoral studies were not managed during a family leave with small children. Everyday life was hard and concentrating on the longer term was impossible.

The female doctoral students told that they had taken their child to day care outside the home and returned to the research work with conflicting feelings. However, they were happy about the opportunity to take the solution they evaluated to be the best from the point of view of the wholeness. In the pressure of the different demands related to work, career and family many women suffer from a guilty conscience when they experience that they are not fulfilling all the demands $[17 ; 20$.

"Of course, you get a guilty conscience. As for the solution, you think that if I leave for work is it bad for my child, is it a selfish solution. It has been partly a good solution in many respects. It has made it easier that I have managed to leave work by 16.00. I would have had a really guilty conscience if I would not even have been with my child in the evenings. I remember, when my child was a little over a year old, I was going back to work, that many people were asking where my child was going and how it was possible for a child so small. Can I organize my life at all that the small child goes to day care and so on ..." 
The women were motivated returning to the research work from family leave. The research work progressed effectively and everyday life carried on. They experienced the research work as a balancing factor amongst other busy aspects of life. In practice, the working days were efficient, compact and short.

During the second child, the planning was clearer than before for some of the female doctoral students. They tried to time the birth of the second child so that it fitted in with the research work, the age difference with the other children and the situation of the family as a whole. At the same time they, however, we aware that it was not possible to time having a child exactly in a certain time frame.

\subsection{The Spouse and His Working Career}

The women interviewed by me regarded the support from their spouses as important even though all the spouses were not familiar with the reality of the research work. The support was versatile, both emotional and concrete. The spouses' educational backgrounds varied but the female doctoral students of my study were the highest educated in their families. Six of the female doctoral students mentioned that their spouses were in responsible positions in the working life and invested unfortunately a lot in their work. Because of this the mother of the family was left with the main responsibility for everyday life at home. The members of the family discussed the situation at work and in education and about their use of time. They tried to pay attention to everyone's wishes and the shared benefit. Some of the women left out the whole doctoral thesis from the internal discussions of the family and from the everyday life. The spouse didn't always know about the stage of the doctoral thesis or even the subject of it.

"Broadly in a way that any a man in the street would react. Also putting down comments, such as is there any sense in researching anything like that. And sometimes there are also quite reasonable or healthy comments, when we are in these own small worlds of ours in the university, then we get to hear the other side. I do not know, whether we discuss very much about these, we do sometimes ... And sometimes he does indeed try to irritate me a little, when I come home he asks if I got that thesis finished yet..."

\subsection{Couples' Relationships in Everyday Life}

In academic couples' relationship private and vocational support are combined at their best but the non-academic couples' relationships also support the one doing the research work [1]. The female doctoral students regarded their relationship as happy, however pressured by everyday life. The role of a wife was a secondary one in a busy everyday life coloured by demands. The relationship was overshadowed, which caused the interviewees some guilty conscience. Own demanding research work, the husband's work career and small children were part of the equation. It was assumed that the everyday life of many families with small children was similar and the mother's research work was not experienced as crucial from the point of view of the situation.

\subsection{Family as a Limitation and Supporter}

The women interviewed by me experienced the family as a limitation and slowing them down but, on the other hand, as a resource which supports and balances the doctoral studies. They told me that the family was important and that they had organized other aspects of life according to it. The women wanted to and were able to organize their life within certain limits. With the family, the time perspective became more flexible, longer and more comprehensive. The research work was effectively carried out in the time that was reserved for it; as a rule it was not desirable nor possible to continue it at home. The family required its share of the attention which forced them to work efficiently and made it possible to remove their thoughts from the research work. During the working hours, one had to concentrate on the essentials matters which promote the research. The willingness to be flexible with the clearly defined working hours was there only in case of extreme hurry.

\subsection{The Researcher Work and Paid Work}

The female doctoral students compared their doctoral thesis work to any given work. The intrinsic nature of doctoral studies was not negatively reflected in the least in the family: the doctoral studies were flexible, they made possible the individual solutions and shifts caused by a family or by other matters. The flexibility eased the management of everyday life, the combining of family and work. The women's objective was still to concentrate on the research work during the working hours and to other 
things at leisure. It was hoped that the time that was allocated for the work would decrease in the future and the family time would increase. Still, a constant hurry and lack of time and even the marginalization of private life are experienced in the families, in particular, in the families of two work careers and of demanding knowledge work [21]. The women in my study were aware of the hurry related to the work and to the demands for the use of time. They were also aware of the conflict between their hopes and the future realities. Even if the knowledge work would, in principle make flexible working possible, the wholeness of several factors and the routine structures of the society direct the everyday use of time of those with a family. The biggest opportunity for the self-motivated organization of the use of time is in the families where the parents' work is flexible and autonomous knowledge work. [21.]

According to their own experience, the doctoral process proceeded frustratingly slowly for those students in the study who carried out their doctoral studies in addition to other work, family and everyday life. The constant pressure to write the doctoral thesis with only a little time was mentally strenuous. They felt pressured by the feeling of wasting time and by the accumulating guilty conscience about wrongly allocated time resources. At weekends, it was possible for them at times to further their doctoral thesis but then they wanted to recover from the week and to spend time with their family. As a solution they saw the scholarship with which they could withdraw from their work and to concentrate on their doctoral thesis as well as to mark limits in their life sensibly. Even though they set loose time frames for writing the doctoral thesis, their intention was to promote the doctoral process effectively when a suitable time and financing came along. The stretching work load weighed down on them above all else in the thoughts and induced doubts about its success.

The idea of combining work and family varied according to the overall situation in life. In spite of the exact boundaries, at times the work took resources from the family and from the other aspects of life. The taxing phase was exhausting and caused uncertainty also about motherhood. Demanding work and intense family life could become a burden, which slows down recuperation. When the situation of one female doctoral student had reached a dead end, the right solution seemed to be to discontinue the doctoral thesis project.

"I am tired of the work, it also comes home. It feels unbearable... If I didn't have children, even though now this is really hard, I don't enjoy this one bit, I might find the ambition. I cannot live in a way that I'm not happy. It is more important to make a decision which keeps me well in my mind. It well could be that if I did not have children, there would be time to recuperate sometimes. I imagined it to be the opposite, when the child was on its way and I was planning the postgraduate studies. I thought that the child would solve the problems. That when I come home, I forget the work and can concentrate better on the essential. I feel that it might have worked for a little while. I lived in a state that how wonderful that even though I have a small child, I can make decisions like this in my life. Now I've become dulled to it and the novelty has worn off, even though the life should be easier, than when I had a small child."

\subsection{The Use of Time And the Importance of Planning}

Please, do not number manually the sections and subsections; the template will do it automatically. Immense inspiration as well as exhaustion are alternately experienced in the doctoral studies [22]. For the female doctoral students in my study the hardships of the different sectors of life were reflected dialogically in the wholeness. Negative experiences of the doctoral process were connected to too sparse time resources, the dragging on and the incompleteness of the research, to the lack of financing or the vicinity of its termination, to the pressure to complete the study and to the comprehensive stress brought on by these factors. Six of the women had at some stage of the process also had thoughts of discontinuing. The students who discontinue the studies are not failures [17], but the reality does not correspond to the preconceptions [23].

As it has been shown above, the interviewees mentioned the use of time as one of the everyday challenges [also 5]. The families negotiated and agreed on the use of time together, even though mainly the woman was responsible for the planning and organizing the families' use of time [also 5]. Women arranged their working hours according to the benefit of the family, even though they emphasized their commitment to their work. The members of the family discussed housework and in several families an attempt was made to share them equally. Still, five interviewees told that they were doing the majority of the housework or even all of it. They were dissatisfied with the situation and hoped for change. They explained the situation even to themselves due to the temporary nature of the situation, family leave or their husband being busy at work. In only one family the man did more housework than the woman. 
The considerations concerning the use of time were partly conflicting. At times they wanted to continue interesting research work, in which case the family was regarded as an interference. On the other hand, they wanted to spend more time with the family and to restrict the working hours. In particular in the final stages of the studies more time was spent with the doctoral thesis. The ones on family leave distanced their thoughts from the research consciously, as their intention was to concentrate on the family life and to return to the research work later. The ones in other work regarded the equation of work, family and doctoral studies as difficult. They tried to reserve time for the research at weekends and planned for the scholarship applications. They were satisfied with the meticulous use of time but it also partly annoyed them. Family restricted the time used for work, as can be interpreted from the following quotation.

"I read some articles at home, in the evening. Not a lot. There is the combining of a family and work in the everyday life, of course, when I have two children and there are my, my husband's and the children's hobbies, and there should be time to fit it all together. I can't work very long days, because I really have to go home."

\subsection{Other Challenges and Advantages of the Whole}

Significant challenges for the female doctoral student with a family are acquiring international experience and creating a career. Qualifying as a researcher requires post doc -experience from abroad. The interviewees told that the threshold to go to the international conferences had become higher. Furthermore, the family reduced the willingness to move and the possibilities to network. The ideas that concern combining a family and a career were twofold. Family provided the opportunity to withdraw from the research work, but on the other hand, family restricted. As the advantages of the doctoral studies interestingness, flexibility and family friendliness were mentioned.

"I have seen it as a resource in work that it can be taken home. When in practice there has been no other work than finishing the thesis, I have often worked at home. I concentrate better there, there are no distracting factors and at the same time I can put on the washing machine and do some small house work. Also the time taken for travelling to work is saved. I haven't taken it slavishly, that I should work from 8 till 4 . For years I worked much longer days, from 9 till 6 and Saturdays on top. When I was pregnant, I used it also the other way round. Days could be 6-hour long. Now I've been working 7-8 hours per day. I've worked so many hours in for years that I can use the advantage "

Setting boundaries and separating the research work from everyday life and from other aspects of life was partly artificial. The mind and the subconscious were busy with the research even though the work was not even physically close. Transition to the 24/7 rhythm flexes the working hours and for its part blurs the boundaries between work and the other aspects of life [5]. The opportunity to choose the suitable ways of operating for oneself would seem to be central.

\section{CONCLUSIONS}

The family increases the continuity of partly fragmented elements in the life of the women studying for a doctoral degree. The women themselves see family both as a resource and as a restricting factor. Both the family and the research work are important and they do not want to give up either of them. Doctoral studies have a positive effect as a rule on the woman's life if she has succeeded in combining her key roles dynamically and comprehensively [cf. 7].

In my study, nine out of twelve female doctoral students write the doctoral thesis as their paid work. For them writing the doctoral thesis is a part of the normal everyday life and it does not control and restrict other aspects of life. It makes possible the exact time delimitations made in everyday life between the research work and the family. The female doctoral students in my study divide their life carefully, their use of time is systematic and they try to be actively present in each situation. They also perceive their own life course as a clear continuum and manage their everyday life with the help of routines. The female doctoral students with a family would seem to have succeeded in combining the family and the research work that is carried out as paid work. The women are not content with only having a family or just the doctoral degree, they want at least to have them both. If the life of the female doctoral student tightens too much, she loosens schedules but holds on to her dreams and her objectives.

It is challenging for the women with a family to write the doctoral thesis in addition to other work, instead, the doctoral studies carried out as main employment suits them well. Research work is free and independent. On the other hand, research work is framed by the given time, economical and 
qualitative outline conditions. The doctoral student can seemingly make individual choices but the different possible consequences should be realized. The competition is an essential part of the doctoral education and research, own knowledge and skills must be made visible, measurable and valuable.

The time management of female doctoral student is efficient, internal agreements and negotiation within the family are central. The challenge indeed is to identify one's own limitations, a mother does not need to stretch to everything. The simultaneous major roles of, in particular, the mothers of small children are burdening. According to my study, the female doctoral students prioritize, the family and their role as a mother are the most important, immediately followed by their own career. They aim for managed everyday life through planning. The fatigue of increasingly young generations and the desire for the slower life style are one of the global phenomena of our time. The same trend is present in the talk of female doctoral students. They make choices, cut out less important matters and spend time concentrating on the important matters. According to my study, the female doctoral students with a family are efficient planners of the use of their time and active makers of plans. In spite of the well thought out choices they are troubled by a guilty conscience from time to time. The possibilities of influencing their own everyday life are important.

The individualizing development is reflected in the families, in the everyday life and the choices of the family members. The recent research has concentrated strongly on the woman's challenges in combining work and family. However, the man's position is also changing - the organization of life course and everyday life apply also to the academic men. They negotiate combining their different roles, balance between the research work and the family and consider the ways of managing. The academic men with families manage the demands which are directed at them by negotiating, compartmentalizing the matters, managing the use of time and by discussing with those close to them [24] as also the women in my study do. The academic fathers want to be actively involved in the everyday life of the family [24]. Combining academic research work and family is still more challenging for a woman, especially when both are at an intensive stage [20], the unsuccessful combining of them is a key reason for leaving the university [25]. The women and men experience combining family and research work as comprehensively challenging and rewarding [24].

The affirmative results I received are largely due to the fact that the majority of the women who participated in my study were writing their doctoral thesis as their paid work. Instead, the doctoral studies undertaken in addition to work and the family require special arrangements. Even though sometimes there are considerations such as "can I organize my life at all", it would seem that the female doctoral students with a family can and they organize their everyday life for the best of their family and themselves within the limits of the alternatives which they themselves are able to influence. The challenges of everyday life can be organized, the bigger challenges are met as matters to be solved. The everyday life of the female doctoral student with a family is made of pacing and choices. The answer to the research task indeed crystallizes: the everyday life of the female doctoral student with a family presents itself as a busy, organized and individual life. For those with a family, the use of time is a challenge in the doctoral studies and its management is the enabler of the success [17], at the same time the preoccupation and slow pace that are part of the academic work must be borne in mind.

\section{REFERENCES [Arial, 12-point, bold, left alignment]}

References [Arial, 10-point, left alignment, upper and lower case] should be cited according to the Bibliography and Citation Style https://iated.org/citation_guide

[1] Husu, L. "Women in universities in Finland: relative advances and continuing contraditions", In M.A. Sagaria (Eds.), Women, universities and change. New York: Palgrave Macmillan, pp. 89111, 2007.

[2] Neumann, R. and Tan, K. K. "From PhD to initial employment: the doctorate in a knowledge economy", Studies in Higher Education, vol. 36, no. 5, pp. 601-614, 2011.

[3] Boud, D. and Lee, A. Changing practices of doctoral education. New York: Routledge, 2009.

[4] Baker, V. and Lattuca, L. "Developmental networks and learning: towards an interdisciplinary perspective on identity development during doctoral study", Studies in higher education, vol. 35, no.7, pp. 807-827, 2010. 
[5] Tammelin, M. Working time and family time: experiences of the work and family interface among dual-earning couples in Finland. Dissertation. University of Jyvaskyla, 2009.

[6] Silva, E. and Smart, C. "The "new" practices and politics of family life", In E. Silva and C. Smart (Eds.), The new family? London: Sage, pp. 1-12, 1999.

[7] Perry-Jenkins, M., Repetti, R.L. and Crouter, A.C. "Work and family in the 1990s", Journal of Marriage and the Family, vol. 62, pp. 981-998, 2000.

[8] Beck,U. and Beck-Gernsheim, E. Individualization. London: Sage publications. 2001

[9] Mayer, K.U. "New directions in life course research". Annual Review of Sociology 35, pp. 413433, 2009.

[10] Macmillan, R. "The structure of life course: classic issues and current controversies". Advances in Life Course Research 9, pp. 3-24, 2005.

[11] Bell, W. Foundations of futures studies. Human science for a new era. vol. 1: history, purposes and knowledge. New Brunswick and London: Transaction publishers. 1997.

[12] Adkins, L. and Jokinen, E. "Introduction: Gender, Living and Labour in the Fourth Shift", NORA Nordic Journal of Feminist and Gender Research, vol. 16, no. 3, pp. 138-149, 2008.

[13] Kvale, S. Interviews. An introduction to qualitative research interviewing. London: Sage, 1996.

[14] Gall, M.D., Gall, J.P. and Borg, W.R. Educational research. An introduction. (7th ed.) Boston: Allyn and Bacon. 2003.

[15] May, V. "Conclusion: Why a sociology of personal life?", In V. May (Eds.), Sociology of personal life. Hampshire: Palgrave Macmillan. Pp. 168-172, 2011.

[16] Chase, S. E. "Narrative inquiry: Multiple lenses, approaches, voices", In N.K. Denzin and Y.S. Lincoln (Eds.), The Sage Handbook of Qualitative Research. Thousand Oaks: Sage Publications, pp. 651-680, 2005.

[17] Leonard, D. A woman's guide to doctoral studies. Buckigham: Open university press. 2001

[18] Beck-Gernsheim, E. Reinventing the family: In search on new life styles. Cambridge: Polity Press. 2002

[19] Sevón, E. Maternal responsibility and changing relationality at the beginning of motherhood. Dissertation. Jyväskylä: University of Jyvaskyla. 2009

[20] Moen, P. and Sweet, S. "From "Work-family" To "Flexible careers": A life course reframing", Community, Work \& Family, vol. 7, no. 2, pp. 209-226, 2004.

[21] Nätti, J., Anttila, T. and Tammelin, M. "Knowledge Work, Working Time, and Use of Time Among Finnish Dual-Earner Families: Does Knowledge Work Require the Marginalization of Private Life?", Journal of Family Issues, vol. 33, no. 3, pp. 295-315, 2012.

[22] Stubb, J., Pyhältö, K. and Lonka, K. "Balancing between inspiration and exhaustion: PhD students' experienced socio-psychological well-being", Studies in Continuing Education, vol. 33, no. 1, pp. 33-50, 2011.

[23] Pyhältö, K., Vekkaila, J. and Keskinen, J. "Exploring the Fit between Doctoral Students' and Supervisors' Perceptions of Resources and Challenges vis-à-vis the Doctoral Journey", International Journal of Doctoral Studies, vol. 7, pp. 395-414, 2012.

[24] Reddick, R., Rochlen, A., Grasso, J., Reilly, E., and Spikes, D. "Academic Fathers Pursuing Tenure: A Qualitative Study of Work-Family Conflict, Coping Strategies, and Departmental Culture", Psychology of Men \& Masculinity, vol. 13, no. 1, 2012, pp. 1-15, 2012.

[25] Armenti, C. "Women faculty seeking tenure and parenthood: Lessons from previous generations". Cambridge Journal of Education, vol. 34, no. 1, pp. 65-83, 2004. 